\title{
La enfermería en salud pública: el caso de la Influenza
}

\author{
The public health nursing: the case of influenza
}

\begin{abstract}
Mtro. Ezequiel Canela Núñez, * Estudiantes de la Especialidad de Enfermería en Salud Publica $2009^{* \star}$, Dra. Maite Vallejo Allende ${ }^{\star \star \star}$

${ }^{\star}$ Coordinador de la Especialidad en Salud Pública. ENEO.UNAM, **Estudiantes de la Especialización de Enfermería en Salud Pública 2009: Aguilar Santiago Ana Angélica, Arzaluz Guadarrama Roció, Bautista Aguilar Margarita, Calvillo Martínez Rafael, Delgado Cerón Anabel, Galicia Buendía Areli, García Jiménez Cristina, García Toro Héctor Hugo, González González Sonia, Hernández Ruiz Antonio, Jiménez Acosta Martha, López Ramírez Fabián, Marcos González Graciela, Medel Romero Brenda Cintia, Morán Hernández Elizabeth, Patiño González Lizett, Rojas Monjaras Florencia, Sandoval Chávez Daniel, Varela Vargas Lorena,

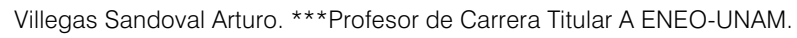

\section{Resumen}

Ante un brote de una enfermedad infecto-contagiosa, el estudio de contactos limita la transmisión de esta. El objetivo de este trabajo fue identificar a los contactos de los posibles casos de influenza en trabajadores de la UNAM para establecer una comunicación y proporcionar educación para la salud sobre medidas higiénicas. Material y métodos: Se elaboro un cuestionario, se estableció contacto con los casos por vía telefónica y se llevó a cabo una visita domiciliaria. Se llevó a cabo un análisis descriptivo de los datos y una descripción de las experiencias y percepciones durante las visitas. Resultados: Se identifico que la mayoría de los contactos eran familiares directos de los casos, que no contaban con un esquema de vacunación completo, ni contra la influenza y la frecuencia de síntomas varió de 1 hasta 4. Comentarios finales: Ante una situacion de este tipo (la Pandemia del Virus de la Influenza Humana $A(H 1 N 1))$ el papel de la enfermera en salud publica es de suma importancia no solo en la búsqueda de los casos y sus contactos, sino también en la orientación y educación de la población en relación a la medidas preventivas

Plabras clave: Influenza, prevención, promoción, salud pública 


\section{Abstract}

In the view of an infectious and contagious disease epidemic, the identification of the contacts limits its transmission. The objective of this work was to identify the contacts of the possible cases of UNAM workers in order to establish communication and provide health education about hygiene measures. Material and methods: A questionnaire was prepared, telephone contact was established with the cases, and a home visit was arranged. A descriptive analysis of the data was carried out, as well as, a description of the experiences and perception during the home visit. Results: Most identified contacts were relatives of the cases, which did not have a complete vaccine scheme, no even against influenza, and the frequency of symptoms varied between 1 a 4 . Final comments: In a situation like this (A(H1N1) human influenza virus pandemic) the public health nurse roll is of great importance, not just in the identification of the cases and its contacts, but also in the orientation and education of the population in relation to preventive measures.

Key words: Influenza, prevention, promotion, public health

\section{INTRODUCCIÓN}

Ante una contingencia sanitaria debida a enfermedad infecciosa como la epidemia de influenza que amenazó a los habitantes de la Ciudad de México, es de gran importancia la identificación de los contactos de los casos índices o primarios, quienes con frecuencia tienen una incidencia y prevalencia de la enfermedad muy superior a la de la población general, debido a que existen las condiciones apropiadas para la transmisión ya que las medidas de prevención y control son inadecuadas. ${ }^{1}$

Uno de los principales motivos para llevar a cabo el estudio de contactos es limitar la transmisión de la enfermedad, lo que también depende de la contagiosidad o transmisibilidad de la enfermedad. Algunas medidas preventivas para los contactos que se han aplicado a otros padecimientos infecciosos como la tuberculosis, la hepatitis A, la influenza A e incluso el VIH y que han probado ser efectivas son la aplicación de vacunas, o gammaglobulina, y el aislamiento. ${ }^{2}$

El objetivo de este trabajo fue identificar a los contactos de trabajadores de la UNAM quienes fueron identificados como posibles casos de influenza, a fin de establecer una comunicación para conocer su situación de salud y proporcionar educación para la salud sobre medidas higiénicas de control.

\section{METODOLOGÍA}

Se identifico y estableció contacto con los casos posibles de influenza y mediante llamada telefónica se solicitó una cita para llevar a cabo una visita domiciliaria.
Se elaboró un instrumento para la obtención de información tanto del caso índice como de sus contactos por los alumnos de la especialidad de Enfermería en Salud Pública de la ENEO-UNAM. En brigadas de dos personas se llevaron a cabo las entrevistas en los domicilios de los casos, previo consentimiento informado de cada uno de los entrevistados.

Se obtuvo información cuantitativa con la que se llevó a cabo un análisis descriptivo de los datos y de manera complementaria se realizó una descripcion de las experiencias y percepciones que se tuvieron durante las visitas domiciliarias.

\section{RESULTADOS}

\section{Características de los encuestados}

En la mayoría de los casos tenían una relación directa con el paciente (2 eran esposo(a), tía materna y padres). El nivel académico de los encuestados en su mayoría fueron estudios superiores, solo había un caso con instrucción primaria. Con respecto a la ocupación la mayoría eran amas de casa, una persona mas era pensionado y otro empleado. De las cinco personas encuestadas 4 contaban con algún tipo de seguridad social. La mayoría (3 personas) acuden a lugares concurridos por lo menos dos veces por semana y su medio de transporte es público (3 personas). Ninguna de las personas encuestadas informó que convivía con animales de corral (patos, cerdos o gallinas). El número de días desde el último contacto con el enfermo vario de 1 a 29 días. 


\section{Características de los casos}

De los cinco casos identificados 4 fueron clasificados como sospechoso y uno confirmado, de acuerdo al reporte de la Dirección de atención a la comunidad de la UNAM. La edad de los casos fue de 18 a 66 años, 3 de los 5 pacientes eran del sexo masculino, todos convivieron con la persona encuestada durante el último mes en el mismo domicilio (Cuadro 1). 2 eran estudiantes uno de licenciatura y otro de preparatoria, 3 eran empleados; uno de ellos con nivel secundaria, uno con bachillerato y otro con maestría. Un dato común en dos de ellos fue que uno estudiaba y otro trabajaba en la misma preparatoria (preparatoria No.5.) Todos acudían a lugares concurridos por lo menos 2 veces a la semana. El medio de transponte que utilizaban era público en 3 de los 5 pacientes y ninguno de ellos había convivido con animales de corral (patos, cerdos o gallinas). (Tabla 1)

Tabla 1. Descripción de datos relevantes caso por caso

\begin{tabular}{|lllllll|}
\hline Nombre & Sexo & Edad & $\begin{array}{r}\text { Estado } \\
\text { actual }\end{array}$ & Estado de inmunización & Lugar de ocupación & Tipo de caso \\
\hline ADPR & Mujer & 24 & Falleció & Sin vacuna & $\begin{array}{l}\text { Facultad de odontología } \\
\text { CU }\end{array}$ & Sospechoso \\
KPV & Mujer & 18 & Viva & Sin vacuna & Prepa 5 & Confirmado \\
DBT & Hombre & 34 & Vivo & Sin vacuna & Museo Centro & Sospechoso \\
RLM & Hombre & 41 & Falleció & Sin vacuna & Dirección de patrimonio & Sospechoso \\
RBL & Hombre & 66 & Falleció & Sin vacuna & Prepa 5 & Sospechoso \\
\hline
\end{tabular}

\section{Análisis de los contactos}

Con respecto al número de contactos, se identificaron desde uno por caso hasta el máximo número de contactos que fue de 13, aunque la persona que tuvo este número de contactos no estaba en su condición habitual de vida pues se traslado a casa de unos familiares. (Figura 1)

De los contactos identificados el 56\% (14) tenían un esquema de vacunación completo, llama la atención que el grupo de contactos más numeroso, la mayoría tenía un esquema de vacunación completo, mientras los grupos con pocos contactos ninguno de ellos tenía esquema de vacunación completo. (Figura 2)

Con respecto al número de contactos con vacuna contra la influenza, la mayoría de ellos (80\%) no contaban con este tipo de vacunas. (Figura 3)

En la tabla 2. se describe tanto el parentesco como el número de síntomas de los contactos y de los casos. En general los contactos eran personas que tenían una relación en línea directa con los casos, a excepción de caso con el mayor número de contactos que en su mayoría eran personas sin relación sanguínea con el caso. Número de síntomas varío desde ninguno hasta 4 en los contactos, mientras que en los casos estos fueron más numerosos.

\section{COMENTARIOS FINALES}

Es bien sabido que la influenza es una enfermedad infecciosa de tipo respiratorio con una elevada tasa de transmisibilidad de persona a persona, que aparece generalmente durante la temporada invernal; sin embargo la ocurrencia de casos fuera de lo previsible puede conducir a una pandemia de proporciones insospechadas, desde leve hasta catastrófica como lo fueron en 1918 la influenza española responsable de 50 millones de vidas o la asiática en 1957 que causó 1 millón de muertes. ${ }^{3}$

Si bien se conocen los mecanismos mediante los cuales se genera una nueva variante del virus de la influenza, el conocimiento básico de cómo éste nuevo virus puede adquirir el potencial de pandemia humana es mínimo y aún mas rudimentario es el conocimiento de las bases moleculares mediante las cuales el virus se transmite y se replica, de tal manera que el desarrollo de una vacuna específica constituye un empresa difícil. ${ }^{3}$

Por lo anterior, las medidas de prevención y promoción de la salud cobran gran importancia ante la presencia de un brote o posible pandemia de influenza, y de manera especial la participación de la enfermera en salud pública quien desempeña una labor fundamental desde la identificación de casos y contactos, el interrogatorio de ambos, 
Tabla 2. Descripción de parentesco y síntomas identificados en los contactos

\begin{tabular}{|c|c|c|}
\hline Caso & Parentesco & No. De Síntomas \\
\hline \multirow[t]{3}{*}{ Caso 1} & Hija & 4 \\
\hline & Mamá & 0 \\
\hline & Papá & 1 \\
\hline \multirow[t]{14}{*}{ Caso 2} & Papá/esposo & 5 \\
\hline & Hijo & 2 \\
\hline & Hijo & 1 \\
\hline & Esposa & 1 \\
\hline & Otro & $4^{*}$ \\
\hline & Otro & 1 \\
\hline & Otro & 0 \\
\hline & Otro & 0 \\
\hline & Otro & 1 \\
\hline & Otro & 0 \\
\hline & Otro & 0 \\
\hline & Otro & 0 \\
\hline & Otro & 0 \\
\hline & Otro & 2 \\
\hline \multirow[t]{5}{*}{ Caso 3} & $\mathrm{Hija}$ & 3 \\
\hline & Mamá & 2 \\
\hline & Hermano & 0 \\
\hline & Abuelo & 0 \\
\hline & Otro & 0 \\
\hline \multirow[t]{6}{*}{ Caso 4} & Papá & 4 \\
\hline & Otro & 0 \\
\hline & Hija & 0 \\
\hline & Hija & 0 \\
\hline & Abuela & 0 \\
\hline & Mamá & 0 \\
\hline \multirow[t]{2}{*}{ Caso 5} & Esposo & 3 \\
\hline & Esposa & 0 \\
\hline
\end{tabular}

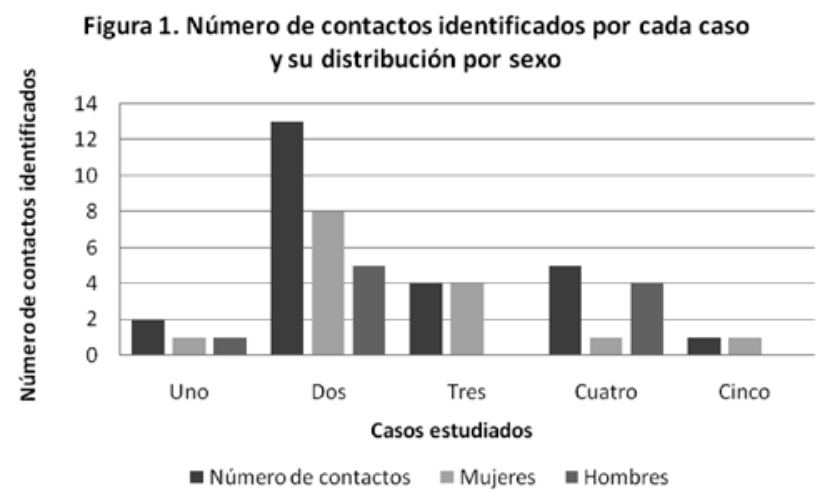

Nota: cuñados, primos, sobrinos, concuños, tíos, suegros, etc
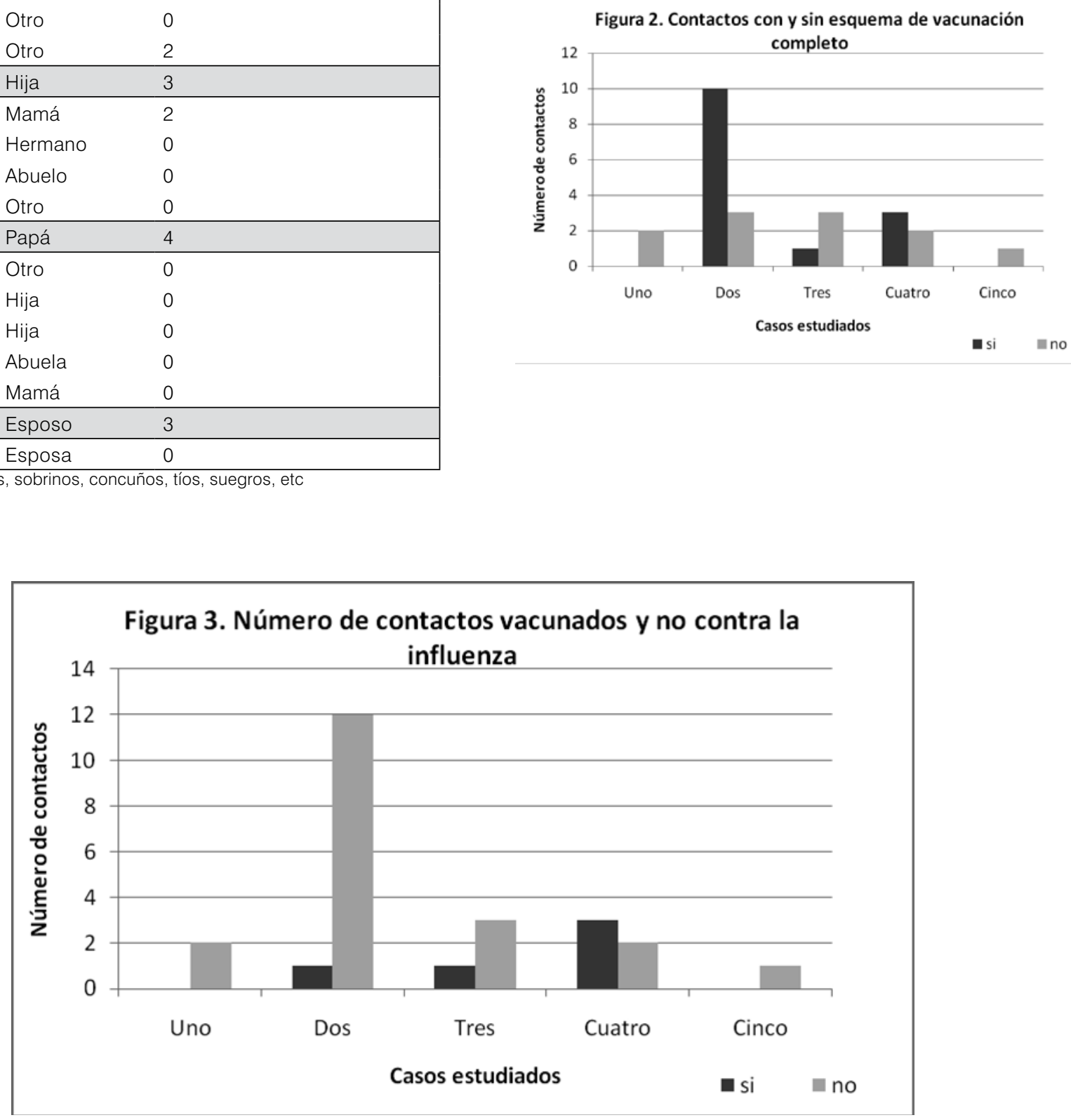
hasta la solución de dudas. ${ }^{4}$ Este profesional ha demostrado a lo largo de la historia su importancia como responsable de estas actividades así como también de la limitación del daño. La aceptación de la sociedad para el trabajo en la comunidad da muestra del valor social que esta le da a la enfermera en salubrista que en los últimos años ha ganado terreno por su importante contribución en esta área.

El presente trabajo muestra las actividades que desarrollaron el grupo de enfermeras en salud pública para la identificación de los posibles casos de influenza ocurridos durante la pandemia de influenza del pasado mes de abril del 2009 en la Cd de México, dentro de la comunidad universitaria de la Universidad Nacional Autónoma de México, así como sus contactos, quien en su mayoría fueron familiares cercanos.

Las actividades de prevención y promoción de la salud que distinguen a este grupo de profesionales de la enfermería, permitieron identificar a los contactos quienes en su no contaban con un esquema de vacunación completo y mucho menos contra la de la influenza ( $80 \%$ no la tenia) esto llama la atención pues es una de las medida más importantes en la prevención de la transmisión de esta enfermedad. Otro dato que conviene menciona es que no obstante la virulencia de esta enfermedad, al interrogar sobre la frecuencia de síntomas en los contactos, solamente uno de ellos informó haber tenido cuatro por lo que se le sugirió que acudiera a los servicios médicos para ser atendido con oportunidad.

La información obtenida durante la visita al domicilio de los contactos mediante la entrevista con cuestionario estructurado de los contactos dejo ver que la mayoría de los probables casos fueron equivocadamente tratados al comienzo de los síntomas, situación que complico su evolución. Por otro lado la confirmación del caso fue un proceso largo y en ocasiones no muy claro para los familiares, aunque una vez confirmado, los contactos fueron citados en las instancias médicas correspondientes para llevar a cabo las pruebas pertinentes en ellos.

Cabe mencionar que dos de los casos identificados provenía de un mismo lugar dentro de la UNAM por lo que se propone realizar una visita al plantel para identificar los factores de riesgo para la comunidad y extender a toda la comunidad la medidas higiénicas preventiva como campañas intensivas de vacunación, lavado de manos frecuente, higiene exhaustiva de las áreas y espacio en donde se concentra un gran número de personas, uso adecuado de cubreboca.
En conclusión se considera que ante una situaciones de este tipo (la Pandemia del Virus de la Influenza Humana $\mathrm{A}(\mathrm{H} 1 \mathrm{~N} 1))$ el papel de la enfermera en salud publica es de suma importancia no solo en la búsqueda de los casos y sus contactos, sino también y en la orientación y educación de la población en relación a la medidas preventivas, que puede ser mediante la elaboración de trípticos o de cualquier otro material informativo, y dentro de las cuales la limitación de contactos, la implementación de medidas higiénicas como el lavado frecuente de manos y la forma correcta de estornudar y de toser, la disposición adecuada de los pañuelos desechables, la aplicación de la vacuna en caso de existir, la identificación oportuna de los signos y síntoma de alarma, ${ }^{4}$ y realizar las referencias de los contactos al sistema de salud, en este caso al universitario.

Como estrategia para la salud escolar se propone la cartilla de salud de los estudiantes y trabajadores a fin de establecer estrategias para el autocuidado basadas en la prevención y la promoción de la salud, y crear la cultura de hábitos saludables. En particular para los estudiantes del área de las Ciencias de la Salud es indispensable mediante un programa que incluya cartilla de vacunación, exudado faríngeo, etc. de manera sistemática a fin de asegurar las condiciones en las que los estudiantes realizan las prácticas o los ciclos clínicos en las diferentes instituciones del Sistema de Salud.

\section{REFERENCIAS BIBLIOGRÁFICAS}

1 Caylá J.A y Orcau A. Estudio de contactos en el siglo XX: se precisan innovaciones. Med Clin (Brac) 2003; 121:494-5

2 Chin J Editor. Control of communicable diseases manual. $17^{\text {th }}$ edition. Washington. American Public Health Association 2000.

3 Salomon R and Webster RG. The influenza virus enigma. Cell. 2009;136:402-10.

4 Secretaria de Salud. Boletín: Acciones para contener la transmisión de la Influenza $A(\mathrm{H} 1 \mathrm{~N} 1)$ en el país. 30 de abril 2009.

\section{DIRECCIÓN PARA CORRESPONDENCIA}

Mtro. Ezequiel Canela Nuñez: ecanela@hotmail.com 